\title{
Visit efsumb.org to view the Euroson School programmes
}

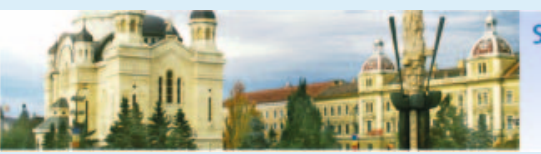

SONO-DERM Dermatologic Ultrasound Course
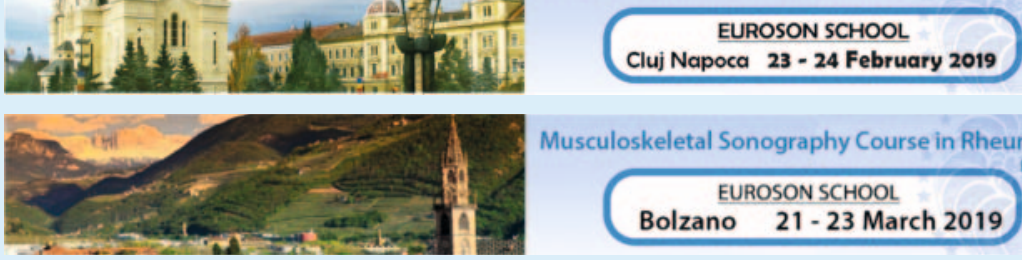

Musculoskeletal Sonography Course in Rheumatology
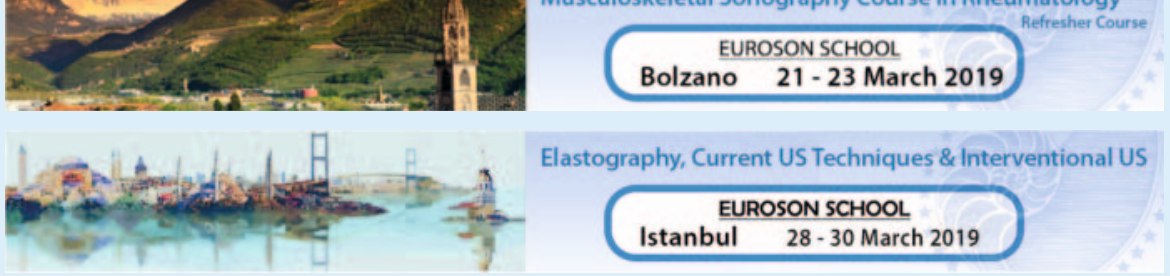

Elastography, Current US Techniques \& Interventional US
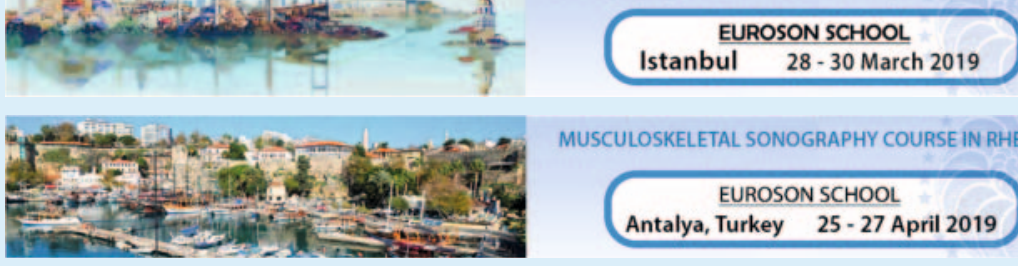

MUSCULOSKELETAL SONOGRAPHY COURSE IN RHEUMATOLOGY
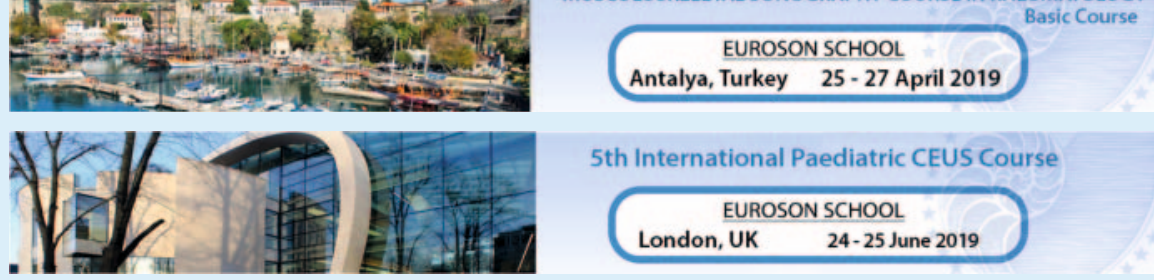

5th International Paediatric CEUS Course

EUROSON SCHOOL

London, UK 24-25 June 2019

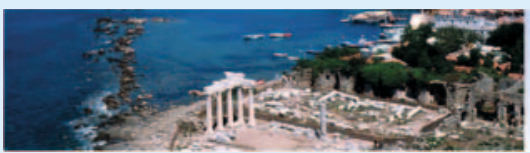

MUSCULOSKELETAL. SONOGRAPHY COURSE IN RHEUMATOLOGY
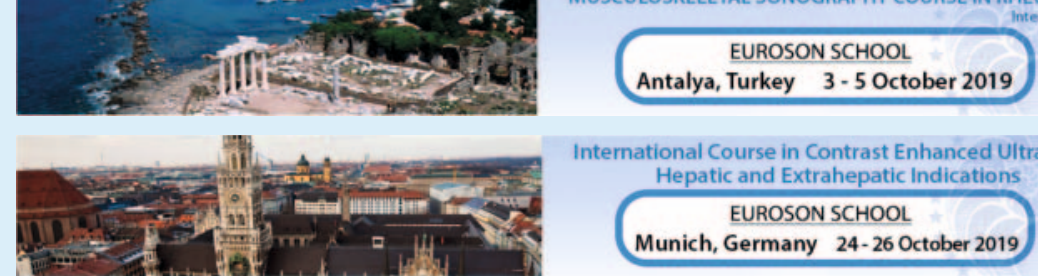

International Course in Contrast Enhanced Uitrasound Hepatic and Extrahepatic Indications

\section{EUROSON SCHOOL}

Munich, Germany 24-26 October 2019

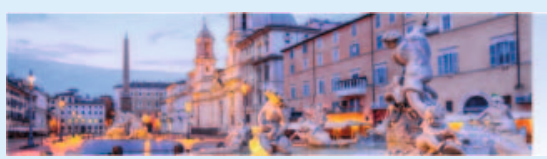

Contrast Enhanced Ultrasound School

EUROSON SCHOOL

Rome, Italy $\quad 15-16$ November 2019 